\title{
“SENTIDO". UNA FRONTERA DE LA FILOSOFÍA
}

\section{Edgardo Albizu*}

"Sentido" es un término claro en apariencia; claridad la suya de lo incuestionado, lo subrepticio. Término del lenguaje acumulado, es significante modesto de significados diversos y por momentos embrollados. Desde el punto de vista filosófico, es tecnicismo oscuro, protopseudoconcepto ofrecido al pensar por el lenguaje como evidente y conceptuante: apoyo material idiomático, polisémico y confuso.

En lo que sigue se enfocará la problemática del sentido desde dos puntos de vista:

1.- Su "Wirkungsgeschichte": gesta efectual, historia o contra-tiempo que produce, efectúa, deja ser memorado, pués el pasado no es vacío; antes bien, deja ser según cada necesidad. (El haber-sido nunca se borra por completo. Si esto no es verdad respecto de toda memoria posible, sí lo es respecto del tiempo mismo). El efecto, evocado por "efectual", no es aquí sólo el resultado, según el principium mágnum, sino lo efectivo, actuante por sí (ejercicio de actualitas, de presentación ahorificante), cualquiera haya sido su causa. En la gesta contra-temporal cuenta lo que va siendo actuante, no genealogías. De tal modo han de comprenderse las referencias históricas (informativas) que se harán.

2.- Su tiempo principial, pro-veedor, localizable tras la necesidad de lo sido, libertad precedente a cuanto se forma, punto en el cual el significante "ser" se rompe. (El nunca-haber-sido siempre emerge ante la espera. Y si lo que no es viene a ser, esto rige para el tiempo mismo en tanto no aparece). "Principio", evocado por "principial", no alude aquí, ante todo, a una causa en sentido estricto, sino al tiempo vigente de una efectividad actuante, de

\footnotetext{
* El texto aquí publicado, que fue leído por el autor en homenaje a Eduardo Briancesco, Academia Nacional de Ciencias de Bs. As., 2004, forma parte de una investigación más amplia, e integra la V Parte del libro: Teoría del contratiempo implosivo, por aparecer en Ediciones del Siglo de Bs. As.

E. Albizu es Profesor de la Universidad del Salvador y de la Univ. Nac. de Gral. San Martín(Juan Francisco Seguí 3542, 16, “D”, 1425 Buenos Aires).
} 
una presentación ahorificante, tiempo respecto del cual la inherencia del efecto no puede prejuzgarse a priori. Y si la gesta contra temporal -historia en sentido habitual- no puede reducirse a una interpretación estricta del principio causal, el tiempo tampoco causa de ese modo; más bien, deja ser, permite a la causa ser causa.

\section{Gesta efectual}

Los recuentos lexicológicos llegan a distinguir en "sentido" hasta tres vertientes semánticas: 1) Organo de la sensorialidad. 2) Órgano del conocimiento de valores, obras y objetos espirituales. 3) Órgano de cumplimiento de la dirección telética del significante, forma inmanente de éste, consistencia objetiva de los sistemas formales. "Sentido" significa, pues, según este primer acercamiento, órgano y forma, centro de funciones y principio estructural, racionalidad del sensorio: enérgueia metafísica de dispensación lingüística, cumplida con lo más concreto. "Sentido" integra, por tanto, desde la idea de irritación fisiológica, aun en nivel celular, hasta el darse cuenta o ahorificar aperceptivo, puesta en acción de una estructura que es para sí su propio ejercicio.

La indisociación epistemo-tecno-empírica del sentido es una antigua experiencia, tanto según su fuente latina, como p.e. en el "arcanos tibi credere sensus" virgiliano, cuanto según su fuente germánica (mittelhochdeutsch), como en los compuestos de "Sinn", p.e. en el Ackermann aus Böbmen (ca. 1400): "böse sinnlose leute" (cap. XVI, línea 2), "sinnereichen meister" (XIII, 6; cfr. XVII, 23), "sinniger man" (XXVIII), 12), lo que no excluye una directa mención a los sentidos, como en "sinneleid" (XI, 6). La raíz indogermánica sent- reúne el ir en una dirección y el ser-afectado. El latino sensus quedó centrado en este afectar que acerca "sentido" a "experiencia" en tanto la direccionalidad quedó dominante en ratio. Sin embargo, la direccionalidad no se excluye de la afección sensible porque el punto experencial es aquello donde, o desde donde, algo es recibido al marchar. El castizo "hacer camino" puede ejemplificar tal convergencia. Así, pues, "sentido" conjuga, y confunde, la aisthesis aristotélica no sólo con la Anschauung sino también con la Urteilskraft kantianas, idea esta que, incluso en su acepción precrítica, permite traducir la fórmula medieval "sinnlose leute" como gente sin tino, sin discernimiento, sin caletre (descaletrada, en suma, y valga el neologismo): que no atina al sentido, des-sensuada, que no marcha en dirección correcta. 
A partir de lo anterior se esbozan dos consecuencias:

1. "Sentido" significa en un campo semántico presidido por la idea de conocimiento cierto, efectivo, aunque sea limitado, lo cual alude a una universalidad concreta y en consumación. Su alcance epistemológico se perfila a partir de la idea de un conocimiento no reductible al modelo de la ciencia físico-matemática, para el cual "sentido" es un concepto metacríticoformal.

2.- Visto según la óptica hegeliana, el "lugar" del sentido debiera hallarse en algún momento del espíritu objetivo. Sin embargo, no aparece en la teoría que Hegel formula de dicho espíritu. Antes bien, el tema de los sentidos se expone en la "física orgánica" (Enz ${ }^{3}$ 『 357-358). En tanto relación externa que se flexiona hacia sí, la sensibilidad es el proceso exterior autodiferenciante en la polisensoriedad de la naturaleza inorgánica. Según esto, los sentidos son: 1) de la esfera mecánica (gravedad, cohesión, calor); 2) de la oposición (olor, gusto); 3) de la idealidad exterior (luz, color) e interior (vista, oído). La nota al $₫ 358$ aclata esta deducción. Es un primer indicio del concepto "sentido" según este sistema especulativo: "Se ha indicado aquí cómo la triplicidad de los momentos conceptuales se transpasa a una quintuplicidad según el número; el más universal fundamento por el cual ocurre aquí este transpaso es que el organismo animal es la reducción de la naturaleza inorgánica, externamente caída, a la infinita unidad de la subjetividad, si bien en ésta es, a la vez, su totalidad desarrollada, cuyos momentos existen como particulares porque ella aún es subjetividad "natural". Los momentos lógicos del sentido pertenecen al espíritu subjetivo: signo, lenguaje (\$S 458-464), condiciones materiales, pues, de la objetividad del espíritu. Podría, por tanto, decirse que, en el sistema enciclopédico de Hegel, los fenómenos del sentido son "aufbebende", superadores de lo vivo en lo pensante, y de éste en lo espiritual-objetivo. Si lo dicho se combina con el primer análisis semántico antes realizado, se perfila más la idea preliminar de "sentido": órgano formante de superación, idea con la que lo propiamente filosófico se centra en el momento hegeliano. El concepto de la superación de sí, hacia mayor plenitud, determina que la representación del órgano formativo adquiera dimensión filosófica: subraya la direccionalidad inmanente, que se verá actuar en los fenómenos de la vida y del espíritu, en tanto nunca son cabalmente ellos mismos sino sólo signos de su plenitud irreal, la acción de un esencial desrrealizarse el ser en dirección a su idea. (La noción de esa direccionalidad superante se esboza también en el 
pensamiento de Hjemslev: "El sentido (mening, trad. alem.: sinn) es, en cada caso, substancia para una nueva forma y no tiene otra existencia posible fuera de la de ser substancia para una u otra forma" (L. Hjemslev, Prolegomena..., 56).

"Sentido" es, por tanto, un tecnicismo oscuro, no por su referencia a la sensibilidad sino a aquello que sostiene como pensables a ciertos objetos subjetivos complejos: conductas, teorías, historias. Es término nunca suficientemente rigorizado, de modo que al punto sólo parece apto para introducir conjuros o anatemas, por un lado, o relevancias no formalizables, por otro. La fórmula "sin sentido" (non sens), usada por el neopositivismo, sirve para condenar teorías que no satisfacen los requisitos canónicos de los contextos de justificación. Hermenéutica y fenomenología, por el contrario, hacen de "sentido" una fórmula cuasi sacramental, condición de viabilidad de sus teorías.

La gigantomaquia epistemológica de este término se gesta, sobre todo, a partir del proyecto neokantiano (badense) de fundamentar las ciencias de la cultura, tenidas en el siglo XIX por dudosamente científicas frente al ostensible rigor de las físico-matemáticas. Y si éstas consumaban el conocimiento del ser, aquéllas debían alcanzar el conocimiento del sentido. Rickert escribe al respecto: "La expresión cultura comparte esta ambigüedad con no pocos conceptos, que no se refieren a meras efectividades en cuanto tales, sino a procesos reales, que a causa de su referencialidad axiológica poseen un 'significado' o un 'sentido' que va más allá de su real existir. Los valores nunca son efectivamente en tanto valores, sino que valen; es decir los valores mismos nunca pueden ser llamados reales, sino solo los bienes en los cuales se 'efectivizan', o 'realizan', y en los cuales los encontramos. De la misma manera, el sentido, que recibe una efectividad en relación con un valor, no pertenece al ser real efectivo sino que sólo subsiste en referencia a un valor vigente y por eso es él mismo irreal-inefectivo. Según esto, por cultura entendemos, en primer lugar, la real vida histórica, a la que se adhiere un sentido que la hace cultura, $y$, además, con eso podemos también significar el 'contenido' inefectivo, irreal, tomado para sí, según es de pensarlo como sentido de tal vida, despojada de todo ser real y según se deja interpretar en relación con los valores culturales. En la 'vida con sentido' coinciden ambos. En su teoría deben estar separados" (H. Rickert, Die Grenzen... (1902), 536). 
En este texto de Rickert aparecen dos puntos esenciales para esclarecer en cuanto al término filosófico "sentido": 1) El ensayo de fundamentar la cientificidad de las ciencias de la cultura en las nociones "valor" y "sentido" y, subsidiariamente, "vida". 2) El carácter sui generis del significado de "valor" -que, despojado de hipóstasis metafísicas subyacentes, cabe tematizar como ficción normativa- y la irrealidad del sentido, presentado como sinónimo del significado.

Respecto de lo primero cabe señalar que este punto de vista, compartido por Rickert con Windelband, recibió una decisiva crítica de Ernst Cassirer, el último neokantiano marburgués, muy libre respecto de los principios de su escuela. En su libro Zur Logik der Kulturwissenschaften, de 1942 (trad. esp. 1951), dice: "Al igual que cualquier otro objeto, los de la cultura ocupan también su lugar en el espacio y en el tiempo. Se sitúan en el aquí y en el ahora, nacen y perecen. Para describir este aquí y este ahora, este nacimiento y esta muerte, no necesitamos remontarnos más allá del círculo de las comprobaciones físicas. Pero, por otra parte, lo físico y precisamente lo físico se presenta aquí bajo una nueva función. No sólo 'es' y 'deviene', sino que en este ser y devenir 'se manifiesta' algo distinto. Y esta manifestación de un 'sentido' que no puede desglosarse de lo físico, sino que en ello se halla adherido y encarnado, constituye la característica común de todos aquellos contenidos a los que damos el nombre de 'cultura"' (68-69). Para explicar la índole del conocimiento cultural Rickert apela, según se vio, a los conceptos "valor", "sentido" y "vida". Desde su filosofía de las formas simbólicas, Cassirer rechaza esta fundamentación y señala que fenómenos como el lenguaje, el arte o la religión no se muestran en propiedad con aquellos conceptos básicos. Después de exponer la idea de "forma interior del lenguaje", según W. v. Humboldt, y de estilo, según Wölfflin, señala que "existe una diferencia muy sustancial entre los conceptos de estilo y los conceptos de valor. Los conceptos de estilo muestran el 'ser' puro, nunca el 'deber ser', si bien en ese ser no se trata de las cosas físicas, sino de las 'formas'. Cuando hablamos de la 'forma' de una lengua o de una determinada forma artística, esto nada tiene que ver, de por sí, con una relación de valor. Puede ocurrir que la fijación de tales formas lleve aparejados determinados juicios de valor, pero éstos nunca tienen una fijación constitutiva para la capacitación de la forma en cuanto tal, para su sentido y su alcance" (98-99). Por ende, si bien ninguna ciencia de la cultura "tiene por meta la universalidad de las leyes, (...) tampoco se contenta con la 
individualidad de los hechos y los fenómenos. Levanta frente a una y otra un ideal propio de conocimiento. Aspira a conocer la totalidad de las formas en que se despliega la vida humana. Estas formas son infinitamente diferenciadas y, sin embargo, no carecen de unidad estructural" (117). En suma: para las ciencias de la cultura la noción de valor es innecesaria; la de sentido, en cambio, se revela imprescindible pero queda indefinida, como en un transfondo clandestino, recubierta por el concepto "forma".

Respecto de lo señalado más arriba en segundo término, se presentan dos tareas, una vez eliminada la noción "valor": 1) Deslindar "sentido" de "significado". 2) Explorar qué implica la irrealidad del sentido, supuesto que se la pueda aceptar como rasgo irrebatible.

La primera tarea se cumple de a poco, tal vez porque no se llega a comprender su importancia. El punto de partida se halla en los escritos de Frege, en el marco de una semántica para la cual cada enunciado es un nombre de la verdad o de la falsedad. 'Digo: los nombres ' 2 ' $=4$ ' y ' $3>2$ ' significan el mismo valor de verdad, que para ser breve llamo lo verdadero. Del mismo modo, ‘ $32=4$ ' y ' $1>2$ significan para mi el mismo valor de verdad, que para ser breve llamo lo falso, así como el nombre ' 2 ', significa el número cuatro. Según esto, llamo al número cuatro el significado de '4' y de '22', y llamo lo verdadero al significado de ' $3>2$ '. Pero del significado de un nombre distingo su sentido. ' $22^{2}$ y ' $2+2$ ' no tienen el mismo sentido, ni ' $22=4$ ' y ' $2+$ $2=4$ ' lo tienen. Al sentido de un nombre de un valor de verdad lo llamo pensamiento o idea (Gedanken). Digo además que un nombre expresa su sentido y significa su significado. Con el nombre designo lo que él significa" (G. Frege, Grundgesetzte... (1893-1903), I 6 s.; transcripto como texto ${ }^{\circ} 42.13$ en I. M. Bochenski, Formale Logia, 382. Cfr. Asimismo G. Frege, "Über Sinn und Bedeutung” (1892).)

Hacia fines del siglo XIX comienza a perfilarse, según se ve en la semántica de las ciencias formales, cierta distinción entre "sentido" y "significado". En su Tratado de semiótica general, Humberto Eco realiza al respecto algunas precisiones ilustrativas:

"El estudio semiótico del contenido se complica muchas veces con un diagrama demasiado simplificado, el conocido triángulo difundido en su forma más común por Odgen y Richards (1923): 
(1)

referencia

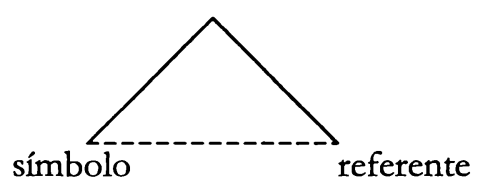

$\mathrm{Al}$ parecer, traduce el triángulo de Peirce:

(2) interpretante

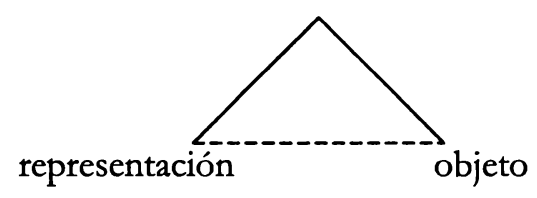

que con frecuencia se considera equivalente al de Frege (1892):

(3) Sinn (sentido)

$(\ldots)$

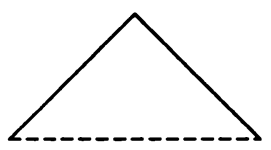

Zeichen (signo) Bedeutung (significado)

Las semióticas de Saussure y de Pierce son teorías de la relación 'semiósica' entre símbolo y referencia (...) y entre el signo y la serie de sus interpretantes (...). Sussure no tiene en cuenta los objetos, y en el cuadro teórico de Peirce ésos entran sólo cuando se discuten tipos particulares de signos como los indicios y los íconos (...). Los objetos pueden considerarse a la luz de una lectura restringida de Frege sólo cuando la Bedeutung se entienda como el objeto real al que puede referirse el signo: tan pronto como se considera la Bedeutung como la clase de todos los objetos posibles a 
que se refiere el signo, como un objeto-type y no como un objeto-token, entonces se convierte en algo muy semejante al contenido" (U. Eco, Tratado... (1976), 100-102).

De las tesis de Frege y sus aclaraciones correlativas se desprende la idea de que "sentido" y "significado" no son sinónimos, pese a identificaciones debidas al lenguaje coloquial, aun cuando lo utilicen los lingüistas, como es el caso del "mening", de Hjemslev, identificable con el inglés "purport". Hay, desde luego, una considerable dificultad para precisar en qué consiste la diferencia por cuanto la definición de un término tiende a hacerse por contrastación con la del otro, y viceversa. Gödel intentó salir de la dificultad mediante la interpretación de bedeuten como "referirse a" y de Bedeutung como "indicación de una sentencia", en tanto Sinn quedó como "sentido", al que definió -según Frege- como "el correlato conceptual del hecho objetivamente existente (o de "lo Verdadero")" (K. Gödel, La lógica matemática de Russell (1944), en Gödel, o.c., 301-2, n. 4 y 7). Aquí la claridad se muestra inherente al desconcierto. En efecto, lo que Gödel tiene por idea de Frege del sentido es, en verdad, su idea del significado, y aquello que considera su idea de referencia es una extrapolación de un contexto extraño, sobre todo porque el nombre -según lo entiende Frege- no indica un objeto sino que expresa su sentido, y tampoco significa tal objeto sino un significado, que, en cada caso, es lo verdadero. La idea "referencia" procede de un contexto no-fregeano, no logicista sino empirista, y disloca el platonismo (lato sensu) subyacente en el pensamiento de ambos lógicos matemáticos. Esto resulta tanto más singular cuanto que, en el estudio citado, Gödel desliza algunas indicaciones conducentes a la precisión de "sentido" y "significado". Eso ocurre cuando aborda la tesis de la inexistencia de clases y sostiene que, en la lógica de Russell, se está ante "uno de los pocos exponentes, llevado a cabo en detalle, de la tendencia a eliminar la aceptación de la existencia de los objetos exteriores a los 'datos' y a reemplazarla por construcciones sobre la base de estos datos. En este caso el resultado ha sido esencialmente negativo; es decir, las clases y los conceptos introducidos de este modo no tienen todas las propiedades exigidas para su uso en matemáticas, a menos que se introduzcan axiomas especiales para los datos (por ejemplo, el axioma de reducibilidad), que en esencia significan que en los datos existe ya el tipo de objetos que han de ser construidos, o se acepte la ficción de que se pueden formar proposiciones de longitud infinita (incluso innumerable), esto es, se opere con funciones veritativas de infinitos argumentos sin que 
importe si se pueden construir o no. Pero una función veritativa de este tipo, ¿qué es sino un tipo especial de extensión (o estructura) infinita, más complicada incluso que una clase y dotada además de un significado hipotético que sólo puede comprender una mente infinita? Todo esto sólo es una verificación del punto de vista antes defendido de que la lógica y las matemáticas (del mismo modo que la física) están construidas con axiomas que tienen un contenido real que no puede ser eludido" (loc. cit. 315-6). Este "contenido real" de los axiomas es, hasta ahora, la idea más precisa de significado; en tanto "propiedades exigidas para su uso en matemáticas" alude a una subyacente idea de sentido, concordante con la de Frege. Se elimina así la idea de referencia, motivo psicogenético (fáctico-epistémico) extrínseco a "significado". En este momento se puede apelar de nuevo al triángulo de Peirce, útil para traducir el lenguaje lógico-matemático al semiótico. Se tiene entonces que "signo" es una fórmula matemática cualquiera, "sentido" las "propiedades exigidas...", o sea los "interpretantes", y "significado", el "contenido real" u objeto constituido en el concepto (p.e. $2^{2}=4$ ).

$\mathrm{Si}$ ahora se integran los primeros resultados de la inspección histórica con los resultados de la semántica de las ciencias formales, se perfila, a modo de hipótesis de trabajo, la siguiente idea de "sentido": órgano formante de superación de contenidos ideal-reales en sistemas operables.

La semiótica aclara remitiendo al uso. Le es inherente el horizonte instrumental. Por eso relativiza los logros lógicos-formales. Dicho según Husserl, la semiótica permanece en una conciencia natural, nivel al que no pertenecen las nociones "sentido" y "significado". Eso no excluye que, en el pensamiento de este autor, no vuelva a encontrase la identificación "natural" de "sentido" y "significado". Sólo de manera lateral sus aportes a la teoría de este último orientan hacia la idea "sentido" (Cfr. p.e. Logische Untersuchungen

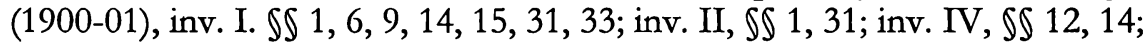
inv. VI, $\iint 1,5,14$ a), 21, 29, 44, 67; Ideen $I(1913)$, $\left.\$ \$ 85,124\right)$. Un indicio valioso se halla en el $\ 51$ de Formale und transzendentale Logik (1929), donde se presenta la diferencia entre lógica de la consecuencia y lógica de la verdad, y en el título la primera es caracterizada como "doctrina del sentido" ("die pure Konsequenzlogik als reine Sinneslebre").

La noción de "sentido" se perfila también en escritos de Dilthey, en los que reaparece la relación con las ciencias de la cultura. Las ideas de 
Dilthey se acercan a las del neokantismo badense, si bien con otra fundamentación metafísica: los principios ya no son los valores sino la vida y la historia. Para Dilthey, "cada vida (humana, histórica, E.A.) tiene un sentido propio. Este se halla en su contexto-de-significado (Bedeutungszusammenhang), en el cual cada presente recordable posee su valor propio, a la vez que se refiere a un sentido del todo en la conexión del recuerdo. Este sentido de la existencia (Dasein) individual es totalmente singular, indeslindable del conocer, y representa, a su manera, como una mónada de Leibniz, el universo histórico" (Der Aufbau... (1910); Ges. Schr., VII 199). A pesar de la implícita diferencia entre "sentido" y "significado", ambos no se deslindan entre sí con nitidez. Sigue habiendo una confusión entre ellos, o una oscilación, que la referencia a la mónada leibniziana no alcanza a precisar.

El neopositivismo no escapa a esta némesis. Carnap, por ejemplo, incluye "sentido" y "significado" en Sinn, sense, y acentúa la designación como vínculo objetivante. Escribe: "Del signo mismo distinguimos, por una parte, el sentido que 'expresa' y, por otra, el nominatum que 'designa'. Esta distinción procede de Frege (texto citado supra, E.A.). (...) Por el sentido de un signo entendemos aquello que los objetos intensionales -es decir, representaciones, ideas, etc., que el signo ha de evocar- tienen en común. 7 y VII tienen el mismo sentido, a saber: el número siete en tanto contenido de una representación o una idea; $5+2$ tiene un sentido diferente. Por ende, (7) es lo mismo que (VII), pero $(5+2)$ es algo diferente" (R. Carnap, The Logical Structur of the world (orig. 1928), en Carnap, The Logical... (ibid.) \& Pseudoproblems in Philosophy, 1967, 74-5). Por "designación", a su vez, entiende una relación "entre aquellos objetos físicos que 'designan' y aquello que designan: por ejemplo, entre el signo 'Roma' y la ciudad de Roma” (34). El término inglés para significado ("meaning") traduce la fórmula alemana, usada por Carnap, "inbaltlicher Sinn" (sentido contenido -a saber, agrego, en el signo) (cfr. 21, n. 20), con lo que se ratifica la confusión derivada de reducir el signo a su carácter instrumental.

De tal modo también se está al borde de la confusión del significado con la cosa, confusión propia de la teoría saussuriana de la arbitrariedad del signo lingǘstico (cfr. F. de Saussure, Cours..., 100), detectada por Benveniste y Jakobson. Este, en efecto, señala que, "en su muy oportuno artículo 'Nature du signe linguistique' (1939), E. Benveniste ha puesto de relieve el hecho de importancia crucial: sólo respecto del observador 
separado, extranjero, el vínculo entre el significante y el significado es una simple contingencia en tanto que, para quien utiliza la misma lengua materna, esta relación llega a ser una necesidad" (R. Jakobson, "A la recherche de l' essence du langage", en VV.AA., Problèmes du langage, 26). En todo lenguaje siempre es arbitraria la relación del signo con la cosa (que, en este contexto, actúa como no-signo); no lo es, en cambio, la imbricación de los aspectos sensoriales (significante) y conceptuales (significado) del signo, vínculo que llega a ser necesario, fenómeno en el cual puede esconderse una clave de sentido, que cuenta explorar. Sin embargo, no basta con no confundir el significado con la cosa; tampoco cabe confundirlo con el sentido. Para no hacer una y la misma entidad del Objekt (susceptible de identificarse con el significado en tanto realitas objectiva, no formalis) y el Gegenstand, y así conjurar el solipsismo tan temido, la reflexión semióticosemántica va desplazando el significado hacia el sentido: metábasis de una a otra orilla (de Silla a Caribdis), que lleva a equivocarse en cuanto a un punto esencial: no hay tierra firme ni centro absoluto. Más bien, en el espacio cuyos marcos extremos son el ente y el sujeto, hay que discernir la subjetividad transcendental del sentido, generadora de transcendencia, y la objetividad inmanente del significado.

Si antes se había llegado a determinar de manera provisional el "sentido" como ejercicio organizador superante, propio de sistemas operables (de una forma que consuma su irrealidad en tanto substancia real comprensible), cabe ahora agregar que dicha substancia es un tejido objetivante. Para discernir las bases transinstrumentales del juego sentidosignificado cuyo ahora relativo es siempre dicho tejido, una contribución importante es lograda por Heidegger en Sein und Zeit (1927). Conforme a la autointerpretación según la cual se desarrolla esa obra, el análisis no se sitúa en planos semióticos ni metacrítico-epistemológicos sino ontológicofundamentales, o sea infrasubjetivo-transcendentales. Así el acceso al significado se cumple desde la estructura de remisiones del Dasein, del estarsiendo preconstituido respecto de la conciencia. Las remisiones tienen un carácter referencial que "aprehendemos como significar" (SZ 87). El planteamiento es inicialmente cercano a la seducción de la cosalidad, así se trate de números y clases, y coincide con la interpretación gödeliana del bedeuten. Pero Heidegger conjura un realismo del significado -inconfundible con un realismo "platónico"-porque piensa la referencia como correlación, y a ésta como un tejido posibilitador de la manifestación. Por eso en un 
primer momento escribe be-deuten; significar es, ante todo, hacer signo: tejer la red y echarla al agua para pescar. En otros términos: no es señalar cosas sino expectativas de ser, señalar capaz de poner de manifiesto lo manifestable; dicho según Hegel: la esencia, no el mero ser. Se pesca lo que la red permite, pero en ella hay algo pescado. Se comprende entonces que Heidegger continúe diciendo: "Al todo remisional de este significar lo llamamos la significancia (Bedeutsamkeit). Ella es lo que constituye la estructura del mundo de aquello en lo cual es, en cada caso, el estar-siendo en cuanto tal" (SZ 87). Puede, pues, colegirse que cada significado es un correlato remitido al todo remisional, del que a su vez cabría distinguir el sentido en tanto armazón formal del tejido correlativante. $\mathrm{Al}$ respecto dice Heidegger: "Cuando el ente intramundano se descubre con el ser del estar-siendo, es decir, cuando ha venido a ser comprendido, decimos que tiene sentido. Más en sentido estricto lo comprendido no es el sentido, sino el ente, o bien el ser. Sentido es aquello en lo cual se sostiene la comprensibilidad de algo. Llamamos sentido a lo articulable en el abrirse que comprende. El concepto de sentido abarca el armazón formal de aquello que necesariamente pertenece a lo que articula un interpretar comprensivo. Sentido es aquello hacia lo cual apunta el proyecto (estructurado por preposesión, previsión y preaprehensión), proyecto a partir del cual algo es comprensible como algo" (SZ 151).

"Sentido" piensa, según el pasaje transcripto, la estructura formal de lo existenciable, de lo que puede darse y permanecer en las aperturas remisionales del consciente-estar-siendo. "Sentido" es, por ende, el significante de la pura remisionalidad funcional que el análisis encuentra detrás de todo signo como insuperable transfondo de los significados, de lo que co-responde a la significancia. En consecuencia, la precisión del sentido depende, en cada caso, de la delimitación de la operatividad direccional en el juego de estructuras semióticas, direccionalidad subrayada en especial por Gadamer (cfr. WM 345). "Sentido" piensa así nexos transcendentales de horizontes existencial-concienciales, nexos en los que se cifra lo "aufbebende" antes señalado. Su condición de posibilidad intrínseca se concentra, ante todo, en los horizontes de "previo". Lo orgánico, formal, superador y operativo se determina desde lo previo, donde yacen las posibilidades de la transformación en significado que autorice el sistema de que se trate: la imbricación significante-significado, que llega a ser necesaria. Desde las pretenciones (de pre-tener; tención: significante desusado de la acción de tener) 
se perfilan las intenciones (conatos) y las intensiones (intensidades) -las direcciones y los "contenidos" ahorificados- fijadas en la marcha. Y en las protensiones (conatos futurantes) se perfila la objetividad: protensiones (posesiones de avance) de proyectos y protensiones de aferramiento ahorificante que fortifican toda experiencia a la vez que le restringen vigencia inmediata, finizabilidad, exhaución. Nada extraño hay en ello. En la multiforme vida cotidiana se lo conoce como la función de la poda, del cortar algo para que crezca. "Sentido" es el corte dado a lo que se mantiene.

Desde la década de 1930 estos fenómenos se enfocan con rigor creciente. En la lingüística se perfila el vínculo del sentido con lo sensorial, sin que esto implique hacer de lo dado por el sensorio una masa amorfa, sino más bien acotar la energía activa de lo que falta en determinado presente primario y actúa desde allende los límites del sujeto: "presencia" actuante de horizontes no ahorificados. (Lo sensorial es el golpe de la ausencia, los proyectiles del espíritu. "C'est la montagne elle-même qui, de là-bas, se fair voir du peintre, c'est elle qu'il interroge du regard": $M$. Merleau-Ponty, L' OEil et L' Esprit, 28; cfr. esp. 70-1, 84-5). En tal contexto resulta decisivo el descubrimiento de la primacía del significante sobre el significado, que acerca a aquél al sentido e inicialmente -sólo inicialmentellega a subordinárselo. Tal descubrimiento brota en contextos y campos variados. Para nuestras necesidades puede bastar su formulación en escritos de Jacques Lacan: "La primacía del significante sobre el significado (...) aparece ya imposible de eludir en todo discurso sobre el lenguaje, no sin que desconcierte demasiado al pensamiento por haber podido, aun en nuestros días, ser enfrentado por los lingüistas" O. Lacan, Situation...; Écrits, 467; cfr. L'instance...; ib. 496-500). "Pues el significante por su naturaleza siempre anticipa el sentido al desplegar en cierto modo ante él su dimensión" (502). Esto supone haber captado "la antinomia inmanente a las relaciones del habla (parole) y el lenguaje. A medida que el lenguaje deviene más funcional, se ha hecho impropio al habla, y al hacérsenos demasiado particular, pierde su función de lenguaje... pues lo que es redundancia para la información es precisamente aquello que, en el habla, hace oficio de resonancia. Pues la función del lenguaje no es en ella (la redundancia, E.A.) informar sino evocar" (Fonction...; ib., 298-9).

Dicho de otro modo: el corte superador, generador, se cumple en y como significante. Si el significado es la planta, el significante es la podadera. A su vez, cada uno de ellos consta de redes de otros órdenes de significados 
y sentidos. El sentido lo da el significante, pero lo supera. Sin podadera no se poda la planta; aquélla permite actuar a la forma superadora, mas desde luego no se identifica con ésta.

Según se ve, la gesta efectual de "sentido" permite el emerger paulatino de lo sensorio-formal del mismo -su carácter operatoriosuperador- como irrealización semiótico-transcendiente, o acaecer del transcender en el signo. El sentido es, por ende, lo operativo-imaginante de la percepción: un captar vicario, propio de la inteligencia, merced a sus redes objetivantes. Dichas redes configuran lo que Kant llamó "esquematismo transcendental", cuya condición de posibilidad es la intuición pura tiempo. Va de suyo, pues, que una profundización mayor de "tiempo" perfila con más rigor el esquematismo pero no lo anula. Si el tiempo es "el concepto que está siendo", según fórmula de Hegel ("der da seyende Begriff", "der Begriff selbst, der da ist": $\mathrm{Ph} 34$ y 429), entonces el esquematismo cala más hondo en la organicidad formativo-superante: su "Stoff" no es el fenómeno sensorial sino el significado. El sentido, cuya protoestructura transcendental es el esquematismo de los conceptos puros del entendimiento, se carga entonces de significancia simbólica, según lo documentan las observaciones de Cassirer. Ésta, por su parte, no sería posible sin las reversiones esquematismo-simbolismo, acerca de las que llamé la atención en mi estudio acerca de la tercera Crítica y la unidad sistemática de la filosofía transcendental (cfr. esp. 21-26). Dicha dinámica encuentra su primera formación en el estudio Ueber symbolische Erkenntnis und pbilosophische Sprache (1790) de Salomón Maimón, quien logra integrar el conocimiento simbólico, el signo y la idea (ed. princeps, 272, 278, 292 ss.) mediante el análisis trascendental de la sinonimia y los tropos (312 ss.). El siguiente pasaje proyecta el esquematismo más allá de Kant e ilumina los transfondos de "sentido": "Todos los conceptos puros a priori son en verdad ideas en tanto podemos representarlos en la intuición simplemente merced a un esquema" (328).

Hegel avanza un paso más hacia la idealidad especulativa de lo que llamamos "sentido" en tanto señala el proceso por el cual la inteligencia se despliega desde la imaginación, en especial desde la fantasía simbolizante, alegorizante y poetizante, hasta centrarse en lo semiótico, en el signo producido por la fantasía. En ese punto se abre la teoría del lenguaje, en tanto el signo es un existir en el tiempo en el que dicho estar-siendo desaparece ("ein Verschwinden des Daseins": Enz" \459). Ahora se tiene el 
estar-puesto (Gesetztsein), peldaño esencial para acercarse a la idea del pensar a través de la memoria (cfr. IS 456-465).

En tanto pre-concepto esquemático-temporal del concepto, lo cual incluye lo semiótico-operatorio superador, el sentido se perfila, en su historia efectual, como inherente al tiempo principal de todo contratiempo. Sustenta así los virajes del pensar filosófico en los que el tiempo busca la parole que relativiza todo decir: pensar que es autosustraerse, huir de lo dicho en tanto se dice.

\section{Tiempo principal}

El origen de la problemática epistemológica del sentido -de su captación, función e índole lógica- puede ponerse en la experiencia de que algo "se escapa" de lo conocido en tanto tal: experiencia del "más" inherente al conocimiento, según se muestra en la constitución de éste en función del crecer, del incrementarse, extremo del dinamismo categorial con iguales títulos que el "menos" de la restricción y la limitación. En suma: experiencia de que en el conocer humano hay más que cuanto acierta a legitimarse según normativas y controles científicos vigentes. "Sentido" alude a eso esencial que se escapa, sin lo cual nada es cognoscible, aun cuando se sustrae a todo intento de conocerlo en sí mismo. Se trata de la experiencia de la negatividad, del omnis determinatio est negatio, de ser por lo que no se es, experiencia cuya concentración positiva en el concepto pone a la Aufhebung, a la negación de la negación, en el centro de la problemática del sentido, paso que al punto, más que esclarecerla, acentúa su extrañeza, su carácter de insondable "pase mágico".

Dado el entrañamiento de las nociones "sentido" y "significante", puede empezarse por esta última para deslindar el campo de "sentido". En mi estudio Prolegómenos para una teoría del significado (2000) la diferencia sentido-significado se concibió desde un juego de factores diversos, no como bloque unitario que pudiera agotarse mediante descripción. En efecto, siempre que el concepto de algo es ab initio experiencia de negatividad, el pensamiento se ve obligado a reconocerse en tanto momento de dicha negatividad, y a actuar para sí como factor constructivo de aquello que se está construyendo, pues sólo experimenta el poiéó quien es su mismo acaecer. En dicho estudio el punto de partida es la oposición lenguajeconciencia, lucha en la que no hay amo ni esclavo, salvo en fugaces 
episodios, pronto disueltos. Esa oposición se concretiza en la protoduación sentido-significado, diferencia cuyo cambiante reflejo de uno en otro concepto es el significante, negatividad del otro en el uno: del significado en el sentido y viceversa. Ambos demarcan el campo de batalla unitario de la gran bicefalia lenguaje-conciencia, donde el sentido se despliega paralelamente a la inteligencia por su aspecto semiótico-sintáctico (zona de constitución de sincronía), en tanto el significado lo hace elevándose desde la conciencia (o antilenguaje, en tanto el lenguaje es anticonciencia) como voluntad de verdad (zona de constitución de diacronía) por su aspecto semiótico-semántico. En tanto la sincronía semiótica cubre con su red el área de concienciación, la diacronía signante rompe dicha red merced al impulso hacia "lo que hace" significado, hacia lo que viene a ponerse en el signo para manifestarse desde él. El sentido es sintáctico, protonivel semiótico del lenguaje. Los significados entran en él y de él salen, en él nacen y mueren. El significado es semántico: siempre extranjero, siempre huésped presto a tornar al padre, para decirlo con una imagen de Novalis. La sincronía es un presente ahorificado, que sólo la sintaxis alcanza a hacer experienciable. La diacronía, en cambio, no sólo es un circuito de contratiempos sino un circuito de tales circuitos, sólo experienciable porque la procedencia desde el pasado -esencia del contra-tiempo- permite el anclaje en el sentido, en la sintaxis; sólo experienciable, pues, en tanto el significado cabe en la sintaxis, aunque sea rompiéndola, como es el caso de la poesía pura. "Sentido" y "significado" son coordenadas transcendentales de lenguaje y conciencia, en los que coinciden sin dominarlos.

Todo lenguaje es un sistema operativo, empírico-superante, finito y contingente, por cuya mediación el ente ingresa al reino del pensar, focalizado como conciencia: presentable-presentado, pensable-pensado, cognoscible-conocido, sabible-sabido, ideable-ideado. A la vez, lenguaje es el sistema de superaciones por el cual el estar-siendo consciente descarga su experiencia (lato sensu) en tanto puede semiotizarse como otras experiencias. El lenguaje no sólo es un sistema de mediación sýn-crónica, con sus tres dimensiones semióticas: sintáctica (presente ahorificado), semántica (red de circuitos contratemporales) y pragmática (red de circuitos ahorificantes de contra-tiempos); es también un sistema de inmediación dia-crónica, con sus tres dimensiones semióticas, isomórficas de las anteriores: pragmática (circulación de la red de circuitos ahorificantes de contra-tiempos), semántica (temporación de las redes de circuitos contratemporales) y 
sintáctica (despresentación contratemporal de presentes ahorificados). La conciencia sincroniza la diacronía del lenguaje y diacroniza la sincronía del mismo. Cada dimensión semiótica tiene, por ende, dos claves de constitución, de lo que resultan seis dimensiones del signo. A su vez, cada dimensión se refleja en el doble juego sincronía-diacronía de la conciencia, movimiento especular según el cual se constituyen "sentido" y "significado". En consecuencia, se tienen doce dimensiones del signo: complejo universo, no simple pantalla; por tal razón, para aprehenderlo habría que captar los matices diferenciales del tiempo.

"Sentido" y "significado" son inherentes al signo en tanto coordenadas de su alteridad sincrónica y diacrónica que se despliega hacia el tiempo sorteando contra-tiempos y apoyándose en ellos: esquemas e ideas de lo translingüístico no dicho y cuasi-pensable. Todo lenguaje es sistema de signos; toda conciencia, de antisignos. Ambos se niegan en sí mismos para sus reflejos: urgencias de lenguaje y antilenguaje. Sentido y significado son ejes transcendentales de esa autonegación, lo otro siéndose y des-siéndose como su propia negación. Si lenguaje y conciencia, cada uno según sus flancos opositivos, se cumplen como no-ser, "sentido" y "significado" dicen-y-piensan dicho cumplimiento en acto. "Sentido" piensa la dýnamis direccional del lenguaje hacia la conciencia, y la dice desde ella, dýnamis que, unificada, se continúa hacia el concepto y la idea pensante, o tiempo que se absolutiza. (El tiempo absoluto, verdadero y matemático, de Newton, y su correlato: el tiempo intuición pura, de Kant, colocan un parámetro relativo a un lenguaje científico y a una ciencia in fier). "Significado", por su parte, piensa la dýnamis direccional del lenguaje hacia lo que se constituye en la conciencia, y lo dice desde ella, dýnamis que, unificada, se continúa hacia el ser y las esencias, hacia la idea real o tiempo-propiamente dicho- que se desabsolutiza. (El tiempo del continuo tetradimensional, de EinsteinMinkowski, y su prototipo: la materia síntesis de espacio-tiempo, de Hegel, colocan otro parámetro relativo a determinado contra-tiempo epistemológico). Puede, pues, decirse, con fórmula escolar, que el lenguaje se transciende hacia el ente y la conciencia, en tanto ésta se transciende hacia el significado y la idea. Lenguaje es sistema direccional del signo hacia las cosas y el sujeto; conciencia, sistema direccional del mismo hacia los significados y la idea: caminos de autonegación en los que, empero, no se destruyen sino que se concentran en sí y en sí reposan.

Por predominar en el lenguaje el significante, lo señalado en él es más 
llamativo. Eso lo hace yacimiento de ambas transcendencias, en las que no se mantiene en sí, mas tampoco se agota en ningún puntual ahora de transpaso. Por eso, en su habitual figura como experiencia parlante, el lenguaje es trans-fondo, repositorio y yacimiento. Su síntesis negativa, o retrotranscendencia -ser al cabo de la exhaución negativa de lo significadoes, por lo general, aquello a lo que se reduce el concepto "lenguaje", aun en la teoría filosófica más osada. Reducir "sentido" y "significado" a dicha retrotranscendencia, o encapsulamiento de ideas -suerte de "petites significations", es una flagrante metábasis eis állo génos: de la construcción creadora al archivo de restos. En ella cae buena parte de las teorías que buscaron en el lenguaje la universal panacea filosófica, metábasis que anula la distinción entre ergon y enérgueia.

Sentido y significado son, pues, tanto más inherentes al lenguaje cuando más lo niegan y se determinan desde metas aniquiladoras de la enérgueia y operativas de su transformación en ergon. En otros términos: el lenguaje me da sentido. Es su única fuente, en cuya consumación desaparece. Muere al dar a luz a sus criaturas, extinción propia del lenguaje en toda su amplitud, no sólo de lengua oral establecida sino también de los sistemas sintácticos de gestos, sonidos "sueltos" e "impresse" (como decía Vico).

Sólo hay sentido en la sintaxis, en sus reglas operantes y logradas. Por eso cada acto de habla (parole, speech act) es amenaza al sentido; con más razón, sus más arriesgadas creaciones: ritos religiosos, discursos científicos, textos filosóficos, condensaciones poéticas. Rozan el sin-sentido, caen en él. Mas esto no comporta escándalo teórico alguno, atentado al buen sentido ni grosería de la inteligencia, según pretenden inquisidores e chaperonas autoproclamados terapeutas del pensar. Sentido sólo hay en la sintaxis que ajusta el juego de los significantes. Puedo saber de memoria el diccionario, almacenar en mí el capital semántico de una lengua, pero si no sé operar con y según sus reglas sintácticas - poiético-prácticas- de sentido, quedo fuera de ella. No ocurre entonces en mí su transcendencia, su transgresión significante del extremo ideal del significado. "Sentido" es acaecer de la síntesis unificadora del eje significante, del adosarse el signo a los espacios de la inteligencia. De hecho, ésta coincide con aquél. El tino, o buen sentido, es inteligencia sensorio-sintáctica; en última instancia, coherencia temporal de los significantes, en la que empieza a develarse el emerger común de tiempo y lenguaje en tanto ahora real. Se encuentra la misma línea recursiva 
en Kant y en Saussure: direccionalidad elemental del contratiempo en el tiempo, abrirse paso hacia la idea, o sea sentido. Por eso el sentido llama al significado. Es el clamor por que el tiempo originario llegue al signo. ("Tan bien hecho este discurso: merece ser verdadero". Nostalgia de la reflexión "se non è vero, è ben trovato"). Hala los espacios semánticos y los estira de modo que activa la transcendencia hacia el concepto, movimiento que incluye feed-back, retorno del significado al significante, pues desde el eje ascendente de lo que se dice parten demandas de concretización de la enérgueia proyectada en cada contexto de parole, hacia la forma cerrada del puro sistema semiótico, que por serlo ya no es sino idea. Sentido es, pues, el significante en tanto me ordena -articula la conciencia- en dirección al tiempo absoluto, en tanto me refiere a él. Es el único momento de referencia en el signo: si éste remite a las cosas, lo hace por mediación del tiempo absoluto, idea en tanto concepto existente, experienciado por todos sus contratiempos. Por eso "sentido" no significa plenitud de significado sino falta del mismo: hueco, vacío. Así se explica el giro "pedido de significado". Lo hace aparecer como plenitud semántica: lo dice la fórmula, por cierto melodramática, "ansia de significado", "libido significationis".

En consecuencia, "sentido" no se identifica con "significado". Es su presentimiento o su huella. Con tal organum formae el lenguaje esboza la predisposición de la conciencia a recibir al ente, recepción que ocurre como significado. Su interpretación radical -según el tiempo- lo muestra como pasado proyectado al futuro, en espera del presente secundario. Por eso el sentido siempre es previo (a todo significado), incluso previo a sí mismo. Y es sin-sentido. La consumación del sentido es el sin-sentido; no la contradicción, el absurdo, el contrasentido, sino la dirección cerrada. La muerte es, por eso, modelo del sentido. Otorga direcciones al vivir, pero ella es sin dirección: cierra caminos. Alcanzarla es consumar el sin-sentido de todos los sentidos existencialmente recorridos.

Dado que el sentido es esencial para la constitución del lenguaje (no hay lenguaje sin sentido), y dado que para la conciencia el sentido es secundario (depende de su fáctico y relativo grado de lingüización), puede hablarse de cierta prioridad existencial del lenguaje sobre ésta. Curiosa tesis pues eso afianza la conciencia, porque el lenguaje introduce la autotransgresión semiótica de los sentidos, la vestidura de lo que se autoafirma como revelante desnudez. Los sentidos son la plena vida en su límite de muerte. Cuentan para la conciencia -unidad de los sistemas de 
significancia- porque, en el lenguaje, los precede el sentido en ellos consumado como sin-sentido, como extinción de la contingencia en el resplandor del significado. El sentido es nivel semiótico primario deslindado de la libido real; posibilita el sentimiento y la significación sin fijarse en ellos sino haciéndolos posibles en tanto en ellos muere. Todo cuanto es, en tanto es, es muerte de sentido, dirección cerrada. En efecto, el sentimiento es el presente primario del sentido que se cierra, según lo revela tesis de Poe: la tristeza es el sentimiento artístico primordial (cfr. mi estudio "Poe, teórico de la composición", en Verdades del arte, 172 ss.). El sentimiento es pathos de sentido, que permite percibirlo, lugar a su vez donde el significado se anuncia hasta fijar en las primeras estribaciones del concepto su aptitud temporante. El enigma de la transformación de "sentido" en "significado", a la que se aludió más arriba, proclama, pues, la profundidad especulativa de aquél: "sentido" nombra la capa semántica del tiempo que se "hace" absoluto -"ser"- por autonegación.

Se comienza de tal modo a comprender por qué, según se mostraba al comienzo de este estudio, "sentido" es una noción desconcertante. Aparece como pasado sustentador en especial cuando el futuro atemoriza con su vacío y su silencio. Por otra parte, empero, a la vez se traslada al futuro para emerger como meta por crear, lograr y cimentar, para lo cual el lastre del pasado ha de anularse. Todo sentido es por eso voluble, vaivén que afecta sobre todo a las ciencias de la cultura, a su comprensión y su hermenéutica, más que a las matemáticas, cercanas a las condiciones lógicas del sentido -las "propiedades exigidas...", de Gödel-, por lo cual pueden generar la opinión de que las postrimerías o ultimidades por investigar son inmutables como los errores inveterados o los interminables sopores.

\section{Frontera y enigma}

Sentido" y "significado" hacen del signo el lugar de mediación entre el "mero" ente y el "solo" estar-siendo. Al congregar en dicho topos, o tiempo total que desaparece, muestran la fuente unificante de lo separado, de los extremos fronterizos. Más tal unificación tampoco es simple: ocurre en las oposiciones lenguaje-conciencia, significante-significado, imagenconcepto, sentido-significado. "Sentido" asume, en su significado, esas negaciones, y envía a los extremos a consumirse en el signo que los nadifica. La existencia-consciente, la caña pensante, carga con el signo como con su 
cruz: el "hombre" construye sentido y coloca significado. Es signo en tanto estar-siendo-consciente. Resplandor del enigma:

\section{"Ein Zeichen sind wir, deutungslos".}

(Hölderlin)

\section{Resumen}

Este artículo enfoca la problemática del sentido desde dos puntos de vista. 1) Su "Wirkungsgeschicbte": gesta efectual, historia o contra-tiempo que produce, efectúa, deja ser memorado. 2. Su tiempo principal, pro-veedor, localizable tras la necesidad de lo sido, libertad precedente a cuanto se forma, punto en el cual el significante "ser" se rompe. "Principio", evocado por "principal", no alude aquí, ante todo, a una causa en sentido estricto, sino al tiempo vigente de una efectividad actuante, respecto del cual la inherencia del efecto no puede prejuzgarse a priori.

Palabras clave: "sentido", "significado", "lenguaje", "tiempo"

\section{Abstract}

This article focuses on the problem of sense from two standpoints: 1) Its "Wirkungsgeschichte", effectual epic, story or setback which produces, makes effectual, allows to be recalled. 2) Its "principial" (opening time), traced behind the necessity of what has been, freedom that precedes all which forms itself, point at which the signifier "being" breaks itself apart. "Principle" evoked as "principial", does not refer here, first of all, to a cause in its strict sense, but to the current time of an executive effectiveness, time in respect of which the inherence of the effect cannot a priori be judged in advance.

Key words: "sense", “meaninig", "language", "time"

\section{Bibliografía. (Obras citadas)}

Albizu, E., "La Critica de la Facultad Discretiva, y la unidad sistemática de la filosofía transcendental", en Filosofía, politica y estética en la Critica del Juicio de Kant. Actas del Coloquio de Lima conmemorativo del bicentenario de la tercera Crítica (comp. D. Sobrerilla), Lima: Instituto Goethe, 1991, 1-27. —_, "Prolegómenos para una teoría del significado", en Albizu, Verdades del arte, Buenos Aires: Baudino/UNSAM, 2000, 87-131. 169-181.

Bochénski, I.M., Formale Logik, Freiburg/München: Alber, 1956. 
Carnap, R., The Logical Structure of the world (orig. Der logische Aufbau der Welt, trad. R.A. George) \& Pseudoproblems in Philosophy, Berkeley \& Los Angeles, University of California Press, 1967.

Cassirer, E., Las ciencias de la cultura (orig. Zur Logic der Kulturwissenschaften, trad. W. Roces), México: FCE, 1951.

Dilthey, W., Der Aufbau der gescbicbtlichen Welt in den Geisteswissenschaften, en Dilthey, Gesammelte Schriften, Stuttgart-Göttingen: Teubner/Vandenhoeck \& Ruprecht, t. VII ( $4^{a}$ ed. 1958).

Eco, U., Tratado de semiótica general (orig. A Theory of Semiotics, trad. C. Manzano), Barcelona: Lumen, $5^{\mathbf{a}}$ ed., 2000.

Frege, G., "Über Sinn und Bedeutung", en Zeitschrift für Pbilosopbie und philosophische Kritik, 100 (1892), 25-50.

—, Grundgesetzte der Arithmetik. Begriffsschriftlich abgeleitet, Jena 1893-1903, 2 vol. Transcripto como texto núm. 42.13 en Bochénski, op. cit. supra.

Gadamer, H.-G., Wabrbeit und Methode. Grundzüge einer philosophischen Hermeneutik, Tübingen: Mohr, $2^{2}$ ed. 1965. (WM)

Gödel, K., La lógica matemática de Russell, en Gödel, Obras completas (introd. y trad. J. Mosterín), Alianza, Madrid, 1981.

Hegel, G.W.F., Phänomenologie des Geistes (ed. Bonsiepen-Heede), en Hegel, Gesammelte Werke, Hamburg: Meiner, t. 9 (1980). (Ph)

—, Enzylklopädie der philosophischen Wissenschaften im Grundrisse [ $3^{\mathrm{a}}$ ed.] 1830 (ed. Nicolin-Pöggeler), Hamburg: Meiner, $6^{2}$ ed. 1959. (Enz $\left.{ }^{3}\right)$

Heidegger, M., Sein und Zeit, Tübingen: Niemeyer, 10 ed. 1963. (SZ)

Hjemslev, L., Prolegomena zu einer Spracbtheorie, München: Hueber, 1974.

Husserl, E., Ideen zu einer reinen Pbänomenologie und phänomenologischen Philosophie. Erstes Buch (ed. W. Biemel), en Husserl, Gesammelte Werke (Husserliana), Den Haag: Nijhoff, t. III 1950.

- Formale und transzendentale Logik (ed. P. Janssen), en Husserliana, t. XVII (1974).

-, Logische Untersuchungen I/II (ed. Holenstein - Panzer, resp.), en Husserliana, t. XVIII (1975) y XIX (1984).

Jakobson, R., "A la recherché de l'essence du langage", en VV.AA., Problemes du langage, Paris: Gallimard, 1966, 22-38.

Lacan, J., Fonction et champ de la parole et du langage en psychanalyse, en Lacan, Ecrits, Paris, Seuil, 1966, 237-322.

- Situation de la psychanalyse et formation du psychanalyste, en Ecrits, ed. cit., 
459-491.

- L' instance de la lettre dans l'inconscient ou la raison depuis Freud, en Ecrits, ed. cit., 493-528.

Maimón, S., Versuch über die Transzendentalphilosophie, mit einem Anbang über die symbolische Erkenntnis und Anmerkungen, Berlin: Voss, 1790 (reproducción fotomecánica : Darmstadt : Wissenschaftliche Buchgesellschaft, 1963).

Merleau-Ponty,M., L' Eil et l'Esaprit, Paris : Gallimard, 1964 (reimp. 1998).

Rickert, H., Die Grenzen der naturwissenschaftlichen Begriffsbildung, Tübingen: Mohr, $5^{2}$ ed. 1929.

Saussure, F. de, Cours de linguistique générale, Paris, Payot, 1972.

Telp, J.v., Der ackerman (ed. crítica de W. Krogmann), Wiesbaden Brockhaus, 1954. 